\title{
Design of Novel Fish De-Scaler System
}

\author{
Soutrik Mukherjee
}

\begin{abstract}
This research is aimed to produce the prototype of a mass manufacturable fish-descaler which would be affordable, efficient and producible. Paper is broadly divided into two parts, first part discusses about preliminary survey conclusions, literature review, problem identification, brainstorming, concept creation and 3-D structure. Standard methodologies like Morphological Charts, Problem statement diagrams, Root Cause Analysis are used to put ourselves in customer(Fish Sellers)'s shoes and understand the root cause of the problem. Based on the problem identified, a solid modeling idea visualization of the particular idea is generated, and individual parts of the model are developed, labelled and dimension specifications were given. Lastly, a 3-D CAD Model of aggregate solid model is developed inculcating the solution for concept visualization. Second part deals with understanding the customer base, market testing, scalability and affordability, mass customization of the prototype. Target customer is predicted according to rough cost of the prototype aligned to the money they are willing to pay for this new entrant. To improve the adaptability, design workings are made visible and transparent. It is essential to mass customize the product in order to maximize scalability, hence a rough roadmap to scalability is strategized at the end.
\end{abstract}

Keywords : Market Testing, Mechanical Optimization, Product Development, Prototyping, Scalability.

\section{INTRODUCTION}

$F_{\text {ish is known as an immanent source of omega-3 fatty }}$ acids and vitamins such as D and B2 (riboflavin)[2]. The American Heart Association recommends eating fish at least two times per week as part of a healthy diet. Apart from health benefits, it is enjoyed by several parts of the India resulting in an enormous market and futuristic possibilities. A fresh, hygienically cleaned, well-scaled fish with minimum distortion get preferred for the further operations in making delicious food or packaging[2]. Descaling is an important stage of fish pre-processing and cleaning which makes it an exciting challenge for budding engineers like us. I, through this work seek to improve some of the morphological and design factors, making the descaling both automatic and manual for greater efficiency and lower maintenance cost.

\section{LITERATURE REVIEW}

As there are two parts to my project, one is the design optimization aspect, another would be the business and

Manuscript received on August 21, 2021.

Revised Manuscript received on August 30, 2021.

Manuscript published on September 30, 2021.

*Correspondence Author

Soutrik Mukherjee*, Undergraduate Researcher, Department of Industrial Design, National Institute of Technology, Rourkela, India Email: soutrik.viratech@gmail.com

(c) The Authors. Published by Blue Eyes Intelligence Engineering and Sciences Publication (BEIESP). This is an open access article under the CC BY-NC-ND license (http://creativecommons.org/licenses/by-nc-nd/4.0/) scaling aspect. Keeping the inherent differences of both these topics in mind literature review is divided into two parts.

\section{A. Design Optimization:-}

1. V. B Bhandari has jotted down several rules, standards and roadmaps for the design of various machine elements which has been helpful in making the project.

2. Companies like Trifisk Manufacturing, Uftokuyi, Jiaozuo Zhoufeng Machinery Co. Ltd, ZZ Allance Manufacturing Co. Ltd, Food Machinery of America, Northrock have been some of the innovators in the field of manufacturing of seafood processing equipment and setups. Some of them has been cited in this section

\section{B. Business and Scaling:-}

1. Online materials from AutofishScaler.com has played an instrumental role to understand the business model to pertain maximum profitability

2. Economics of descaling studies published in Journals such as International Journal of Fisheries and Aquatic studies, Cambridge University Press and JSTOR Collections were also handy

\section{PROPOSED WORK}

Fishing is an ancient practice that dates back at least to the Upper Paleolithic period which began about 40,000 years ago, presently it is also a customary daily food in many parts of the world. The ever-growing variety and demand for fish is a colossal testament to the enormity and future prospects of the particular industry

\section{A. Primary Survey and Problem Identification}

Primary survey is done by going to the nearest fish market and asking the fish seller questions relevant to the direction of research. This is an important step because it helps in forming the user demographics, morphological charts and user need analysis.

\section{B. Questions Asked}

1) What is the problem with current de-scaler?

2) How many descaling tools/practices do you use?

3) What is the initial and maintenance cost of current de-scaler that you are using?

4) How much time does it take to descale (assuming it's a very commonly scaled fish like Catla and SilverCarp)?

5) How much money are you willing to pay for an automatic de-scaler?

6) Is there an electrical socket at your stall?
Published By:

Blue Eyes Intelligence Engineering and Sciences Publication (BEIESP)

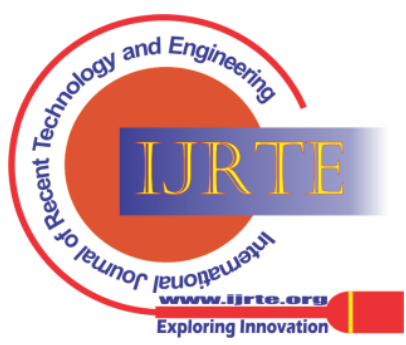




\section{Design of Novel Fish De-Scaler System}

\section{Data Visualization}

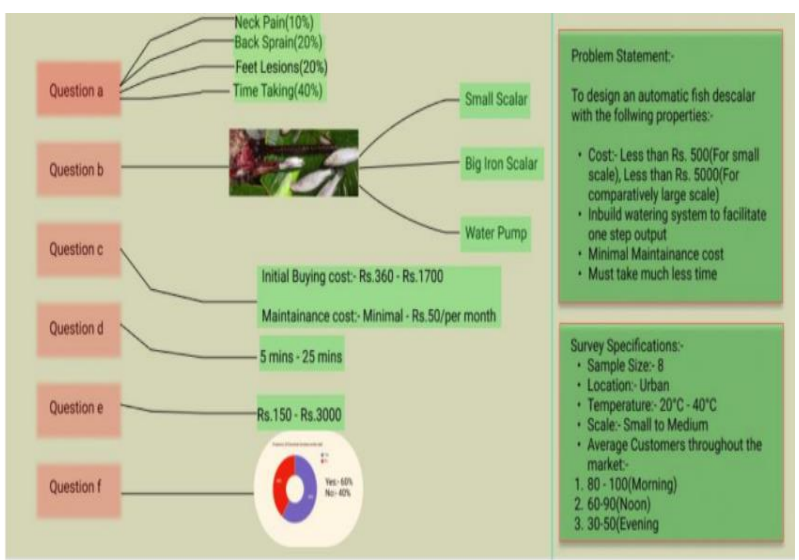

Fig.1 Problem statement and survey specification

\section{Concept Development}

Morphological Chart:- The current idea is broken down into various sub-parts and the sub-parts are analyzed to understand which alternative has to be implemented in the final prototype.

Table- I: Morphological Chart

\begin{tabular}{|c|c|c|c|}
\hline Functions & Alternative-1 & Alternative-2 & Alternative-3 \\
\hline Type of motor & DC & $\begin{array}{c}\text { Unrolled Stator Liner } \\
\text { Motor }\end{array}$ & AC \\
\hline Transport of mass & Conveyer & Power Screws & Fixed \\
\hline $\begin{array}{c}\text { Supply Control } \\
\text { Body/ Frame }\end{array}$ & Electrical & Manual & ManualElectrical \\
\hline $\begin{array}{c}\text { Translational motion of the } \\
\text { machine }\end{array}$ & Fixed & Rectangular & Cylindrical \\
\hline
\end{tabular}

There are 3 broad sub-divisions: -

1) Turning division- There are 3 alternatives namely,

- Gear system

- Strap Drive

- Normal Rope system

2) Displacement of fish division- The displacement of fish and some other residues like scales, non-edible fish parts, fins are to be moved along the machine:

- By gravity

- By artificial blower

- Facilitative Piping

3) Supply Controls division- The amount of fish to be entered in the machine could be controlled using:

- Capacitive displacement sensor

- Photodiode array sensor

- Semi-proximity sensor

\section{E. Design Specification}

\section{a) Perforated cylindrical structure:}

The cylindrical drum can be considered as the core structure of the system. It is made in such a way that perforations act as the descaling agent of the fish. A mechanism has been introduced at one face which facilitates the opening and closing of drum. This whole structure is made from stainless steel to give it the utmost strength and descaling ability as well as non-rusting property

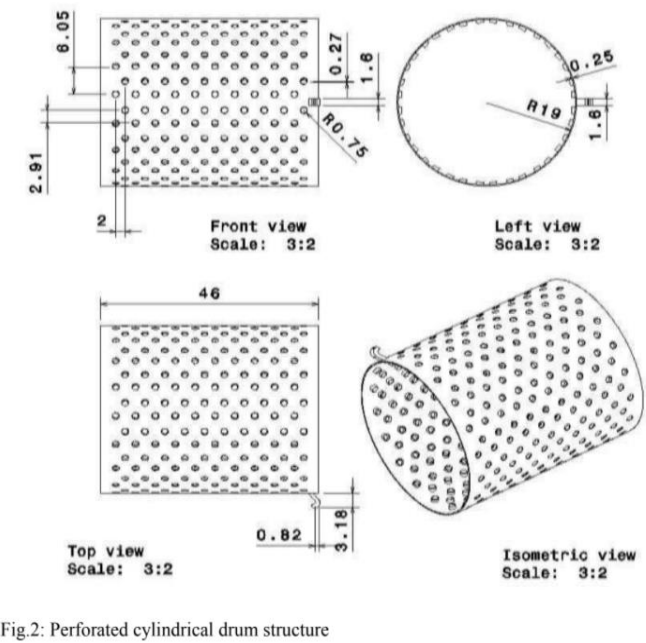

Various data regarding the size of the fish, and the market my product wants to target were analyzed and accordingly the parameters like shape of perforation, drum length, diameter were decided[5]. Since our target market is for small to medium scale, keeping that in mind, the dimensions are shown in the Fig. 2

The pattern it follows is X-Y pattern with a gap of $6.05 \mathrm{~cm}$ between $\mathrm{X}-\mathrm{X}$ or $\mathrm{Y}-\mathrm{Y}$ and around $2.91 \mathrm{~cm}$ between adjacent $\mathrm{X}-\mathrm{Y}$ which give the structure a balance between strength and performance efficiency of descaling.

b) Design of strap drive:

Transmission of power takes place by the shaft and similar to the cylindrical structure, it is also made up of stainless steel. A mechanism is generated in which the electrical energy is converted to rotational energy of the core structure resulting is constant contact of respective perforation with the surface of the fish resulting in descaling and later washing of the fish due to up-flow fluid (here water) pressure.
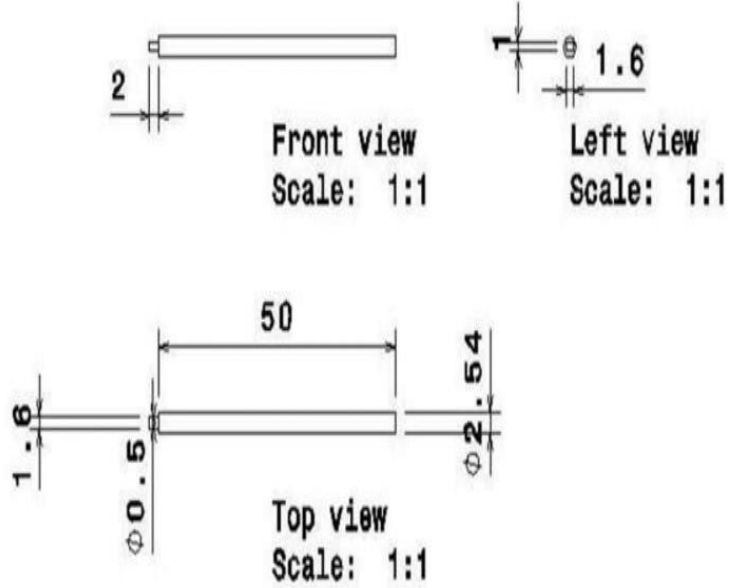

\section{Fig.3: Top, Front and Left View projections of the drive shaft}

c) Structure where the whole system would be kept:

The whole assembly of components is placed compact in a tub of plastic material. The material of sturdy propylene can be used as it resists odor. It serves a rigid base for all the parts mounted on to it. The tub holds water up to a certain indicated level.

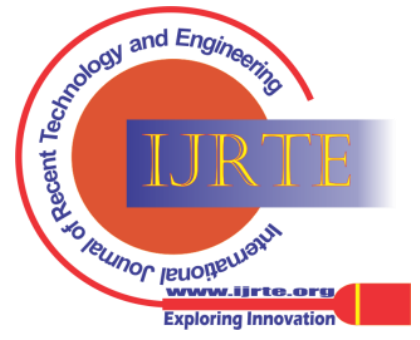




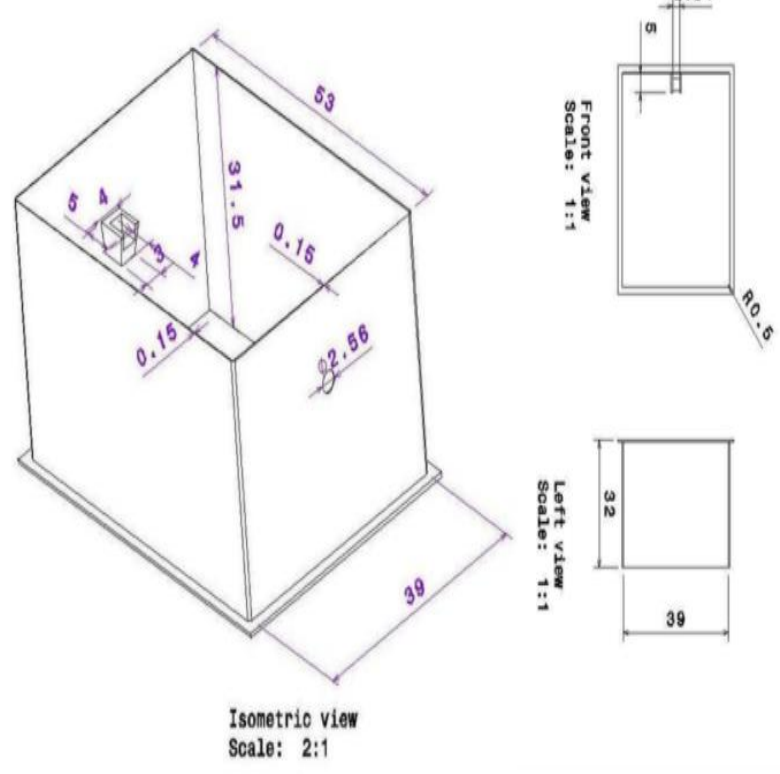

Fig.4: Structure where whole system would be kept

\section{F. Final Structure}

This project was aimed to design a novel fish descaling system by taking into consideration the particular problems fishermen face during the overall descaling process.

It is kept in mind that the overall descaling process involves not only removal of scales but also washing and initial procession before selling to the customer CAD Model is made to show the concept development using software tools like:-

\section{- CATIA V5}

- Fusion 360

- Tinker CAD

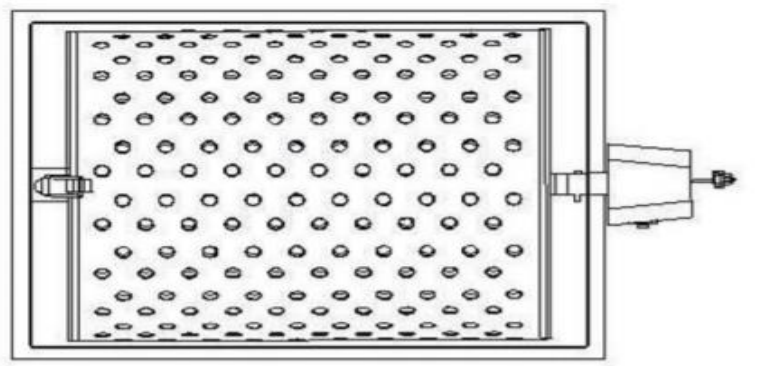

Scale: $3: 2$

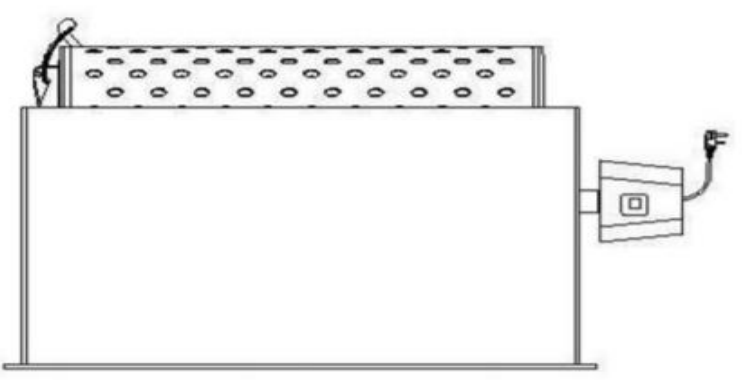

\section{Front View}

Scale: $3: 2$

Fig.6: 3D Sketch Model of the structure

The final prototype would look something like this:-

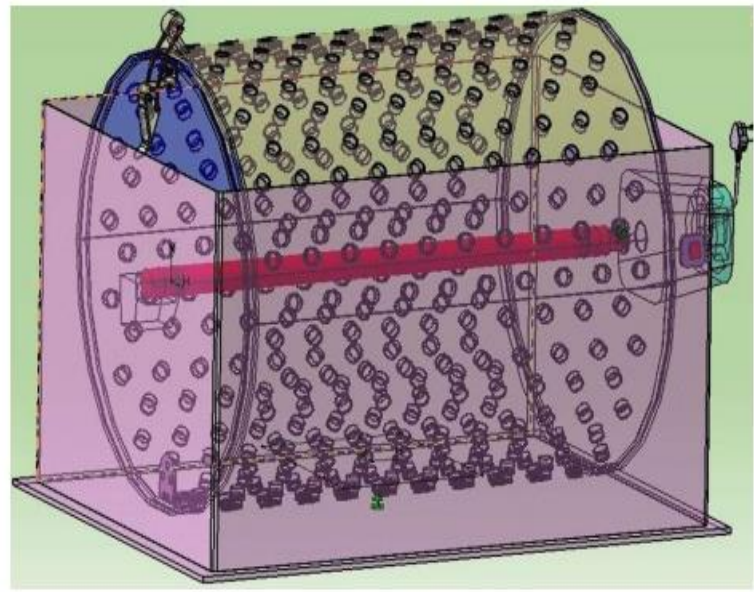

Fig.5:3D CAD Model

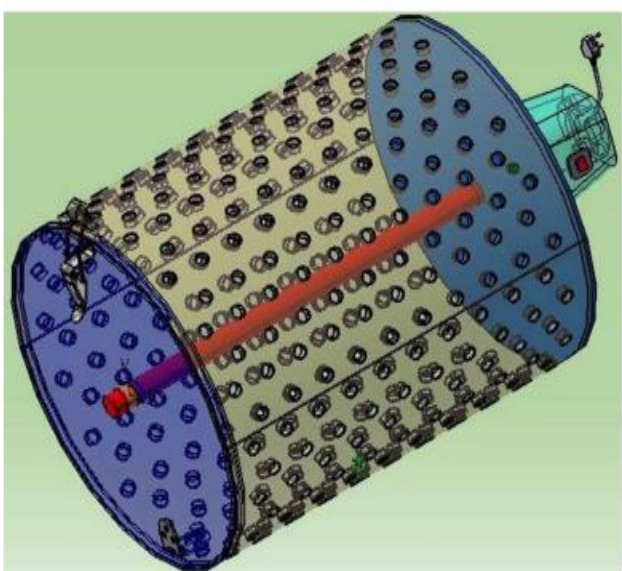

It can be estimated that the current structure will carry 5-6 fish of medium length at once to produce rotational motion. If the fish load is more than 9 , the rotational power produced by the shaft wouldn't be as much as necessary resulting in either partial descaling or taking more time than expected. The similar structure can be increased to scale with inculcation of bigger motors to have its benefits in large scale applications. But if the load of fish remains constant whereas the motor efficiency and power input is multiplied, then the per capita cost of fish is also increased. So, a balance has to be kept between cost of the system vs the efficiency of fish descaling to generate a feasible and profitable business model.

\section{LIMITATIONS}

Like all other designs, this design is very likely to have faults and shortcomings which is expected to get improved at the initial user testing phase. However, while developing the prototype these are the following mistakes that came to my notice.

a) Cost Factor:- This design is likely to cost on the upper side of Rs. 5000 which wouldn't often be affordable by local fish market.

- Another important factor which makes the product competitive to other alternatives is that, it has better efficiency and takes less time. It also has minimal maintenance cost. So, in the long run this design is likely to give more output compared to other traditional alternatives

Blue Eyes Intelligence Engineering and Sciences Publication (BEIESP) 


\section{Design of Novel Fish De-Scaler System}

b) Availability of Electricity:- The design requires electricity for its operation. So, the markets where electricity(110V) is unavailable it couldn't be used. A mechanism can be done which would enable manual descaling however in that case the efficiency would be drastically reduced

c) Adaptability and Acceptance:- Tools used while descaling the fish is more or less the same from time immemorial. There has been a stagnation in improvement of fish descaling apparatus, and stalls have been using almost similar tools through generations. It is pretty likely that there can be some resistance to a new entrant which is radically different from anything they used earlier

d) Production Challenges:- The major challenge while making this is to design the assembly that would create the whole machine. The production has to be done in three stages:-

- Low Scale Individually:- Individual parts are made using particular tools for the specific part that is made

- Medium Scaled partly mass manufactured/partly individual:- Mass manufactured small assembly is built consisting of machines which is synchronized and creates a resultant effect facilitating the production of design

- Large Scale mass manufactured:- Mass manufactured large scale automation assembly consisting of machines which would produce our design in a large scale.

e) Business Angle:- As mentioned earlier in the long run, this design is likely to give more output compared to traditional sources. The customers(fish sellers) has to be made aware regarding the long term benefit of the design through advertising, one-to-one interactions, and visually understandable manuals.

\section{CONCLUSION}

Fish and other aquatic animals are essential to the food and economic security of over 800 million around the world. Descaling of fish is an important step while pre-processing stage of the fish. It is astonishing to see that, though having an evergreen market, exponentially rising with increasing population, the innovation is very stagnant. Reason being, either enough research hasn't been done or there is an adaptability factor which results in resistance of new technology in this particular sector Lastly, the main aim of this project was to improve myself and try to uphold the general charm of scientific thinking to the fullest of my abilities.

\section{REFERENCES}

1. N Manimehalai, Mohammad Tanveer, M Sivakumar, S Sabanayagam and P Jagan, "Fish De-scalers: A review"

2. K. Dhanapal1, G. Vidya Sagar Reddy, Binay Bushan Naik, G. Venkateswarlu, A. Devivaraprasad Reddy and S. Basu, "Effect of cooking on physical, biochemical, bacteriological characteristics and fatty acid profile of Tilapia (Oreochromis mossambicus) fish steaks"

3. Wilbert Fortune, Stephen Kasukusa, "Design of a fish descaling machine for small and medium scale farmers"

4. James Barlow, Carol Barlow, "Portable And Rechargeable Fish Scaler", U.S. Patent 0,143,939 A1, Jul 31, 2003

5. Nilesh Gaikwad, Tanbir Ahmad, Govind Yenge, Ajeet Singh, "Design, Development and Performance Evaluation of Fish Descaling Machine"

6. Tanbir Ahmad, Nilesh Gaikwad, Yogesh Kumar, Rahul Kumar Anurag, "Ergonomics design and development of poultry dressing table for hygienic processing"
7. Piotr Bykowski and Daniel Dutkiewicz, Gdynia Poland, "Freshwater fish processing and equipment in small plants"

\section{AUTHORS PROFILE}

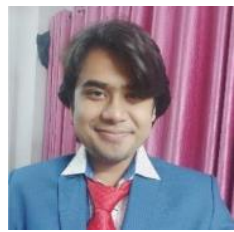

Soutrik Mukherjee, I'm currently in my final year of undergraduate engineering curriculum at NIT Rourkela, India, majoring in Industrial Design and minoring in Mechanical Engineering. I have received several accolades for my academic endeavors including the medal of academic excellence for securing 1st position in my department. I have been selected from a pool of vast applicants as a Summer Research Fellow(SRF) in the coveted Indian Academy of Sciences, Bangalore where my work involved "Algorithms to estimate Laser Keyhole Welding profile". I also had the golden opportunity to intern at IIST(Indian Institute of Space Science and Technology), the space-tech wing of ISRO, on "Numerical Studies of Laminar Fluid Flow". Currently I'm working as an undergrad researcher at IIT Kanpur on designing and modal analysis of an experimental set-up for bubble drop coalescence. My scope of interest includes- Vibration and Control, Structural Analysis, Fluid Mechanics and Flows, Heat Transfer, Product Design

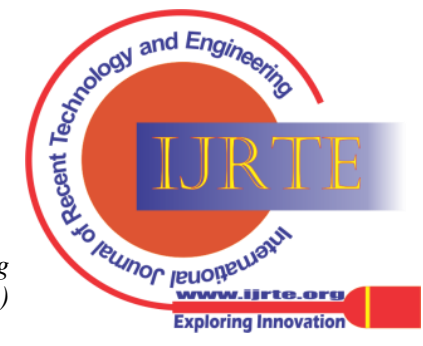

